\title{
Synthesis of RGO-supported molybdenum carbide (Mo2C-RGO) for hydrogen evolution reaction under the function of poly (ionic liquid)
}

Yongli Sun, ${ }^{\dagger}$ B Baoli Wang, ${ }^{\dagger}$ Na Yang, ${ }^{*}$, Xiaowei Tantai, $^{\dagger}$ Xiaoming Xiao, ${ }^{\dagger}$ Haozhen Dou, ${ }^{\dagger}$ Luhong Zhang, ${ }^{\dagger}+$ * Bin Jiang, ${ }^{\dagger}$ Deqiang Wang ${ }^{\S}$

${ }^{\dagger}$ School of Chemical Engineering and Technology, Tianjin University, Tianjin 300072, China

$\$$ Collaborative Innovation Center of Chemical Science and Engineering, Tianjin University,

Tianjin 300072, China

§ Shenglong chemical co. LTD, Tengzhou, 277500, China

Corresponding author:

Name: Na Yang

E-mail: yangnayna@tju.edu.cn 


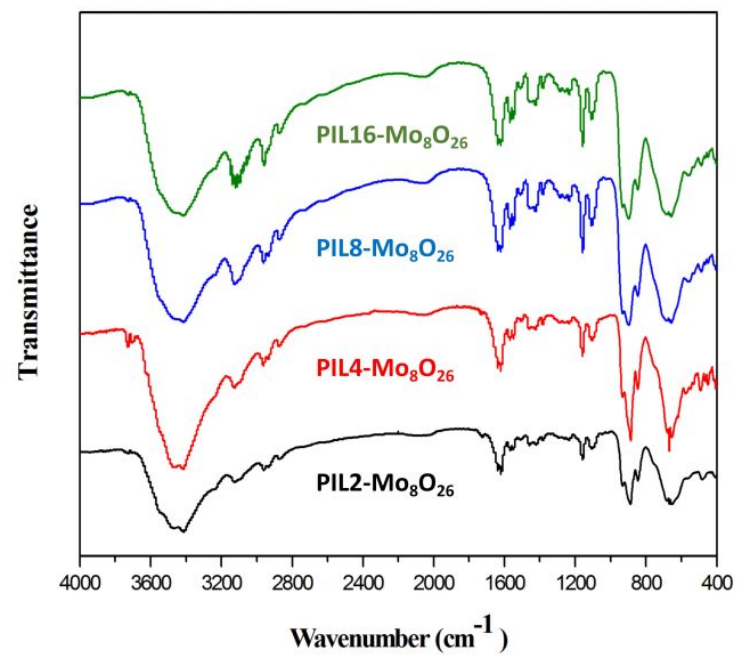

Figure S1. FT-IR spectra of PIL2- $\mathrm{Mo}_{8} \mathrm{O}_{26}, \mathrm{PIL} 4-\mathrm{Mo}_{8} \mathrm{O}_{26}, \mathrm{PIL} 8-\mathrm{Mo}_{8} \mathrm{O}_{26}$ and PIL16- $\mathrm{Mo}_{8} \mathrm{O}_{26}$.

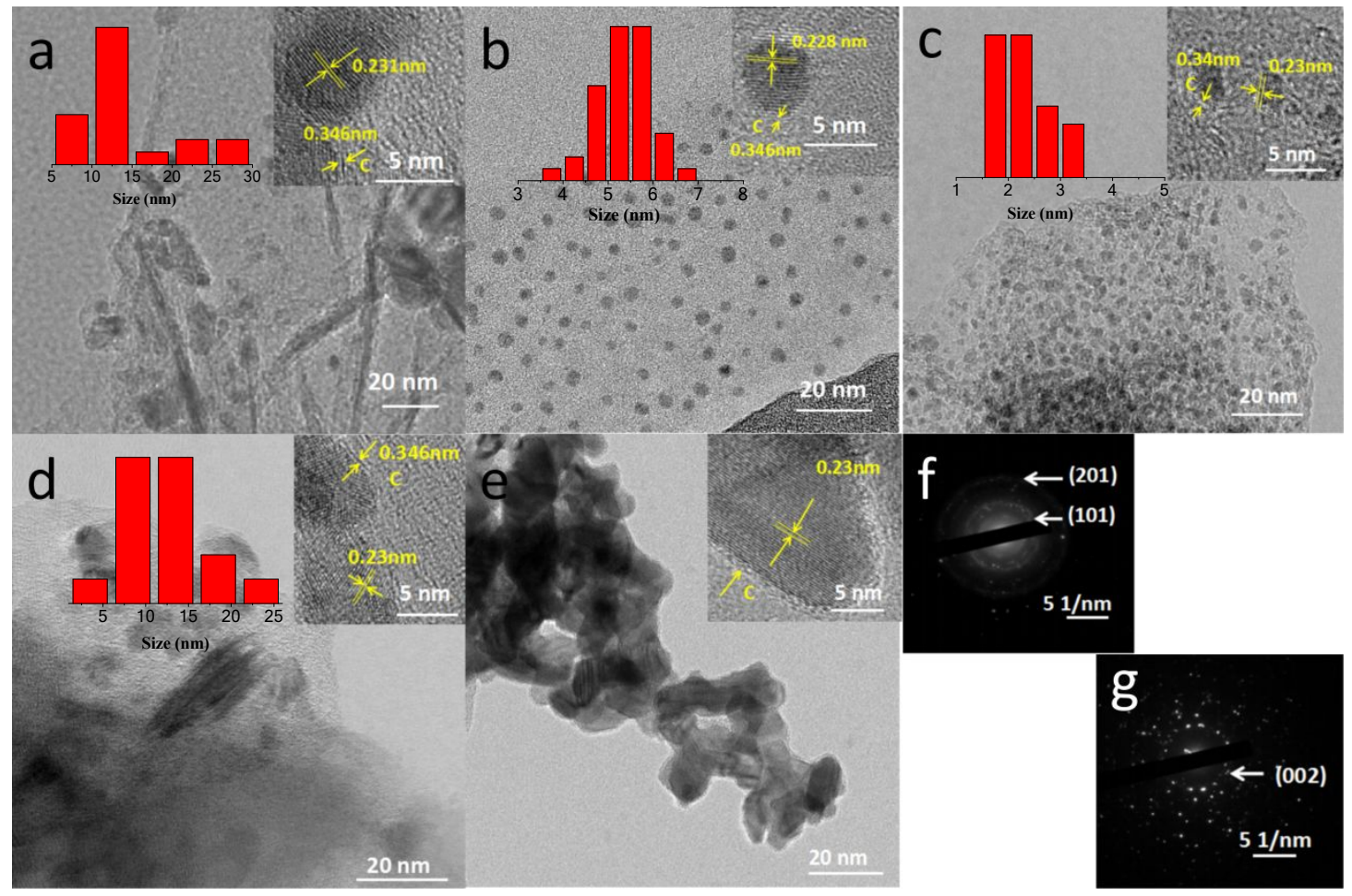

Figure S2. The HRTEM images (a-d) of $\mathrm{Mo}_{2} \mathrm{C}-\mathrm{RGO} @ 2, \mathrm{Mo}_{2} \mathrm{C}-\mathrm{RGO} @ 4$,

$\mathrm{Mo}_{2} \mathrm{C}-\mathrm{RGO} @ 8$ and $\mathrm{Mo}_{2} \mathrm{C}-\mathrm{RGO} @ 16$, respectively. (e) The HRTEM images of $\mathrm{Mo}_{2} \mathrm{C}$.

(f) FFT patterns of $\mathrm{Mo}_{2} \mathrm{C}-\mathrm{RGO} @ 8$ and (g) $\mathrm{Mo}_{2} \mathrm{C}$. Inset: distribution of particle size. 


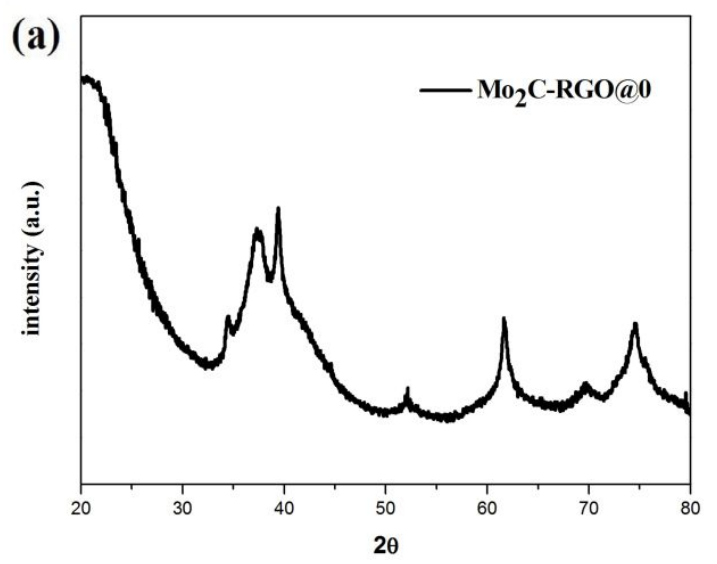

(b)

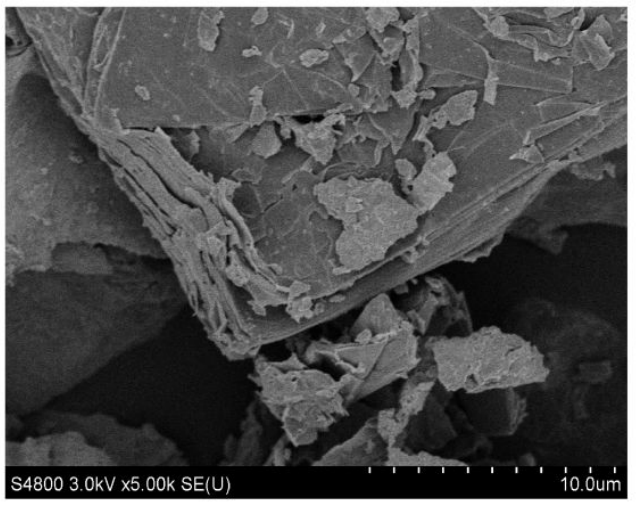

Figure S3. (a) XRD patterns and (b) SEM image of $\mathrm{Mo}_{2} \mathrm{C}-\mathrm{RGO} @ 0$.

(a)

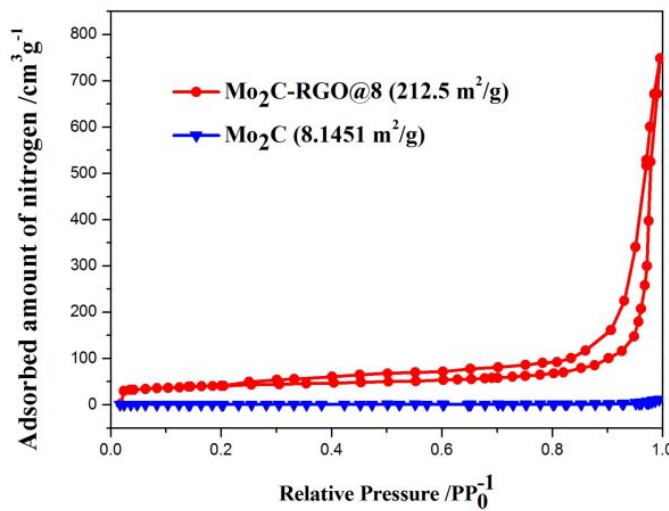

(b)

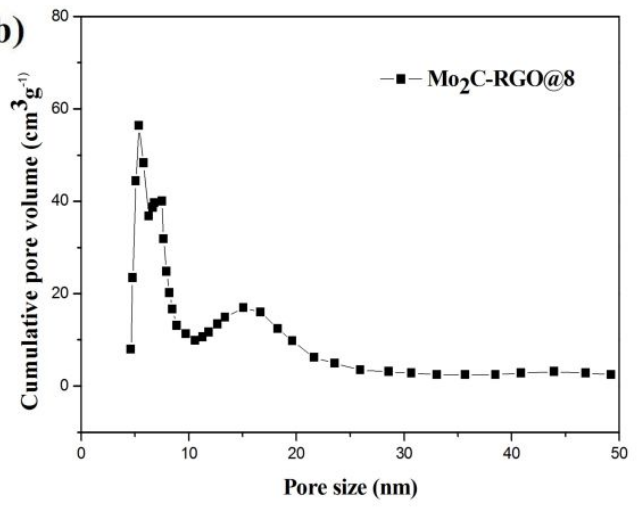

Figure S4. (a) Nitrogen adsorption-desorption isotherm curves with calculated BET surface areas and (b) BJH pore size distribution plots.

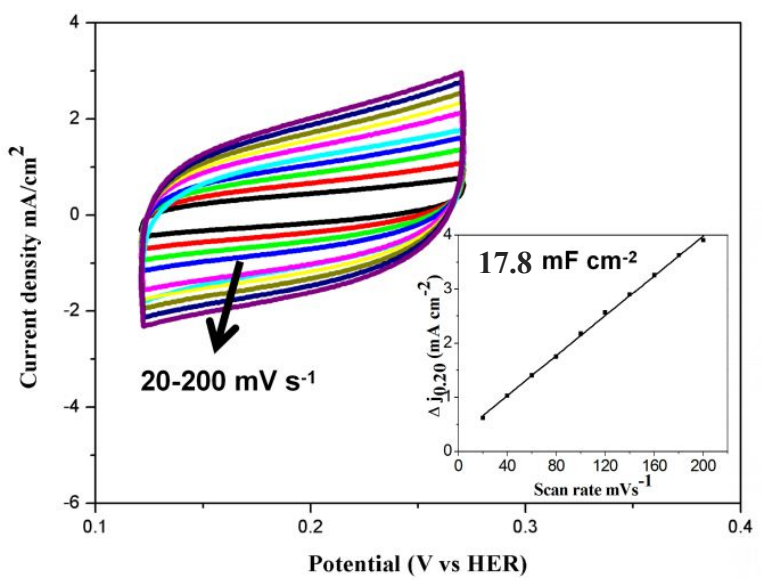

Figure S5. CVs of $\mathrm{Mo}_{2} \mathrm{C}-\mathrm{RGO} @ 8$ with different rates from 20 to $200 \mathrm{mV} \mathrm{s}^{-1}$. Inset: the capacitive current at $0.20 \mathrm{~V}$ as a function of scan rate for $\mathrm{Mo}_{2} \mathrm{C}-\mathrm{RGO} @ 8$. 

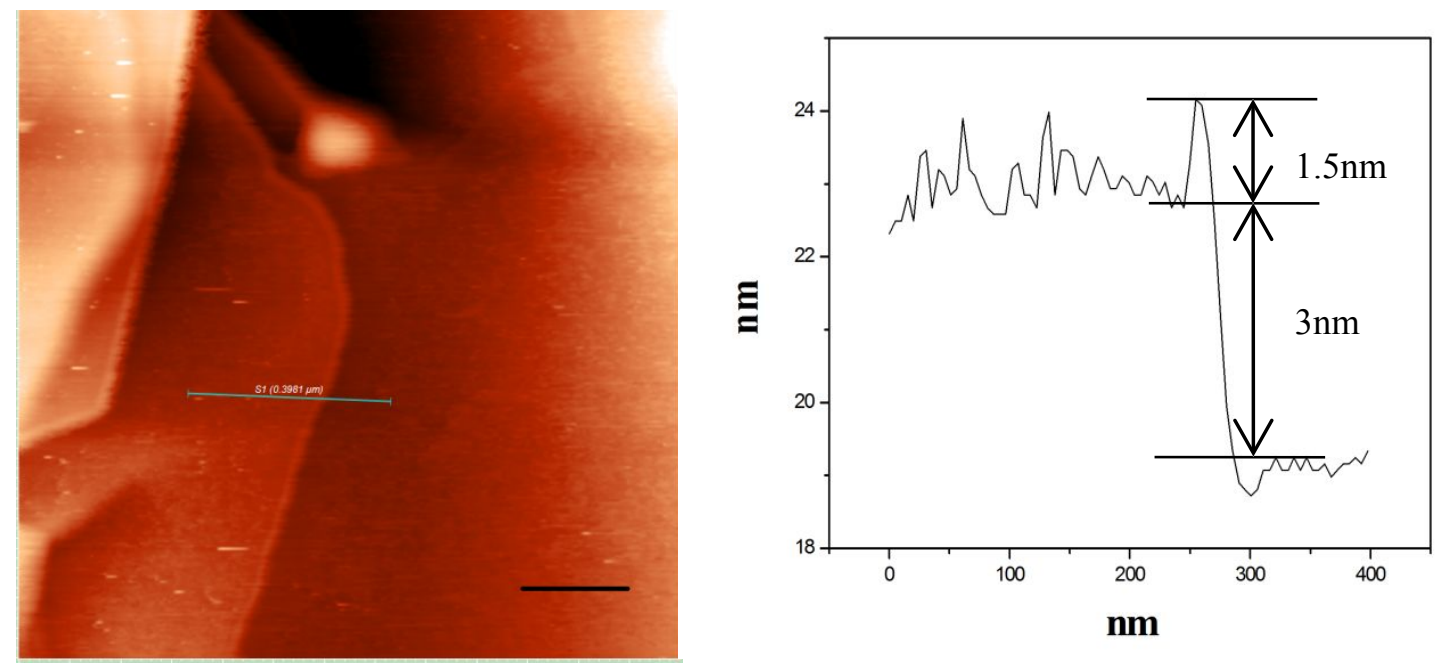

Figure S6. AFM images of $\mathrm{Mo}_{2} \mathrm{C}-\mathrm{RGO} @ 8$. 